\title{
Artigos
}

\section{Um Olhar Antropológico sobre o Hábito de Comer Fora}

Janine Helfst L eicht Recentemente o alimento tem surgido com mais freqüência na pauta de discussões

Collaço da Antropologia em geral, já que durante alguns anos não houve um intenso interesse NAU-USP sobre o tema. Atualmente, é possível acessar uma ampla produção acadêmica procedente de diversos países, envolvendo questões que tratam da alimentação, do alimento, do comer, do corpo etc, assuntos que também estão sendo focalizados em nosso meio e que vêm gerando importantes trabalhos na área ${ }^{1}$.

Os enfoques utilizados para tratar essas questões são compostos de diversas facetas, pois abordam o tema não só do ponto de vista das mudanças geradas pela introdução de novos produtos alimentícios e tecnologias industriais, mas também se atêm ao modo pelo qual o alimento é consumido. Nesse sentido, interessa sobretudo o conduzir uma refeição fora de casa, hábito que embora não seja um fenômeno exclusivo de nossa época ${ }^{2}$, tornou-se extensivo a uma parcela maior de pessoas que o incorporaram ao cotidiano, especialmente das grandes cidades.

Ao lidar com as representações do comer em restaurantes de comida rápida ${ }^{3}$ localizados em praças de alimentação de shopping-centers, este trabalho tenta aproximar-se da diversidade urbana que uma cidade como São Paulo abriga, postura reforçada ao se lembrar que as praças de alimentação apresentaram um crescimento acentuado a partir de meados da década de 1980 e se consolidaram durante os anos seguintes, tomando importância fundamental para os shopping-centers e sugerindo transformações nas dinâmicas do comer ${ }^{4}$.

Para tanto, este texto pretende ser uma breve reflexão sobre os dados de campo coletados nesses espaços ${ }^{5}$ nos períodos de março/junho de 2000, abril/ Campos 4:171-194, 2003. julho de 2001, dezembro de 2001 e janeiro/março de 2002. Os trechos de entrevistas 
J anine Helfst Leicht Collaço

que aqui serão utilizados foram recolhidos nessas diversas etapas com pessoas que estavam realizando suas refeições em praças de alimentação.

\section{COMER}

O alimento é o combustível de nosso corpo e sua ingestão, após uma série de combinações baseadas em diversas lógicas, de exclusão, inclusão, eixos temporais, lugar, preparo etc, concretiza-se no ato de comer que constantemente nos confronta com o risco, com a insegurança, ao mesmo tempo que delimita fronteiras, revela diferenças. "O alimento é uma substância liminar" afirmou Lupton (1996:16), alimentar-se é o momento no qual o que está fora é consumido ou , na concepção de Fischler (1990), incorporado, pois é através da boca que o mundo penetra no eu. Trata-se de um processo que pode gerar insegurança ou medo, pois é através do princípio da incorporação que as qualidades atribuídas aos alimentos penetram em nosso mundo interior, de acordo com nossos valores, idéias, concepções, visão de mundo.

Comer é um assunto universal por excelência. Tal prática se reveste tanto de um sentido prático, atendendo às necessidades do corpo, como também simbólico, embora os significados atribuídos não sejam compartilhados de modo equivalente, determinando o que se deve comer ou não. Sahlins (1976) e Harris (1985) mostraram o que é bom para comer ou não. Harris defendeu que os alimentos tidos como "bons para comer" são aqueles que reúnem uma relação custo/benefício adequada e são privilegiados em função das condições ecológicas presentes em uma certa região, proporcionando as diretrizes do que é conveniente para o consumo. Discordando dessa posição, Sahlins sustenta que é a lógica simbólica que organiza a demanda, já que as demais "qualidades" serão agregadas posteriormente ao produto. Na realidade, o sistema produtivo em conjunto com o esquema simbólico de comestibilidade é o que coordena o que é comestível ou não, e sua posição em determinado sistema alimentar.

Frente à realidade que se apresenta em praças de alimentação, a abordagem de Harris não se mostrou uma ferramenta adequada para enfrentar a complexidade do sistema produtivo atual e colocando a questão do custo/ benefício em uma posição pouco cômoda ${ }^{6}$. Em seu trabalho, o autor aludiu muito rapidamente à questão das empresas transnacionais e à introdução de produtos exógenos, acreditando ser possível manter a mesma argumentação de custo/benefício, "lo bueno para comer es lo que es bueno para vender" (1985: 327), afirmação contestável especialmente ao se lembrar exemplos de fracassos de redes transnacionais no Brasil e sucesso em seus países de origem, como Arby's, Pizza Hut, Kentucky Fried Chicken (KFC). 
As praças de alimentação oferecem aquilo que é bom para comer, organizado sob uma lógica cultural específica, e a introdução de novos produtos precisa passar pela aprovação dessa lógica cultural. É nesse diálogo que ocorrem as apropriações e transformações, não de modo aleatório ou homogêneo, mas seguindo as orientações simbólicas presentes que não deixam de considerar as motivações pessoais, os objetivos e particularidades de cada situação. As mudanças nos padrões alimentares impostas pelo ritmo de vida moderno e urbano condicionam em parte o comer ao determinar horários, distâncias etc, mas não deixam de estar vinculadas às representações do comer pré-existentes e que podem flexibilizar-se em contato com distintas variáveis, conforme já observado por Garcia (1993; 1997). Na esteira das transformações das cidades, os restaurantes de comida rápida ingressam em cena para atender pessoas que trabalham, estudam e dispõem de pouco tempo para uma refeição, normalmente efetuada fora de casa em função das distâncias, do trânsito complicado, da dificuldade de circulação, o que desenvolveu o surgimento de "necessidades" como rapidez, higiene, conforto, segurança, preço acessível, liberdade de escolha oferecidos pelos restaurantes fast-food.

A praça de alimentação e os restaurantes ali instalados proporcionam certa homogeneidade, já que oferecem um comer rápido, a um preço acessível, com pratos considerados de boa qualidade ou, pelo menos, razoável. Essa avaliação é reconhecida e comum entre os comensais que ali efetuam refeição. Embora não tenham laços sociais mais profundos, partilham uma leitura expressa nesse hábito. Essa leitura é possível por fazer parte do repertório da maioria das pessoas provenientes de uma classe média urbana e que passam por problemas semelhantes impostos pelo viver na cidade.

Ao mesmo tempo que essas características similares alinham a experiência do comer em praças de alimentação, também se verifica a heterogeneidade exposta através dos diferentes alimentos, do preço, das decorações, dos estilos de vida que se misturam. Contudo, ressaltou-se que a ida à praça de alimentação é acionada por duas motivações principais e definidas a grosso modo como necessidade e lazer. Percorrer tais espaços em diferentes horários e dias da semana expôs essa oscilação claramente - como, por exemplo, nos horários de almoço durante a semana em que predominam pessoas que trabalham ou estudam e à noite, quando as pessoas que ali se encontram são tomadas de outro ritmo, jantam sem pressa ou apenas ficam conversando em uma das mesas da praça. Nos fins-de-semana o ambiente transforma-se e incorpora outro ritmo, delimitado pela família, pelas compras que são realizadas no shopping, pelos horários de cinema ou teatro, pelo uso dos brinquedos eletrônicos nas pracinhas dedicadas às crianças etc.

Esse caráter pendular apresenta-se de dois modos, alguns entrevistados, sobretudo aqueles que trabalham ou estudam e permanecem fora de casa durante boa parte do dia relatam que comer em praças de alimentação é 
uma forma acessível de efetuar uma refeição longe de casa, ao mesmo tempo rápida e de acordo com noções mínimas de higiene. Eles não costumam ir em outros horários à praça de alimentação. Para outros, a associação desses espaços com divertimento ou lazer é imediata e lá efetuam uma refeição devido ao fato de ser uma alternativa menos dispendiosa que restaurantes tradicionais, possibilitando atender os diversos gostos da família ou de membros de um grupo de amigos. São, também, locais de encontro para sentar e beber, às vezes comer algo enquanto se coloca a conversa em dia; atendem pessoas que moram sozinhas e procuram movimento e circulação, além de não constrangê-las no comer sem companhia; atraem outras que não gostam de cozinhar e tampouco dos serviços de entrega de comida em casa, os deliveries.

Essas condições refletem-se também na noção de "refeição ideal"7 subjacente às várias motivações que condicionam o uso de restaurantes fast-food em praças de alimentação. Quando é feita uma refeição, almoço ou jantar, vinculada a alguma obrigação que não permita retornar para casa a fim de alimentar-se, verificou-se uma tendência a valorizar o ambiente doméstico, no qual é possível poder comer de maneira saudável e adequada, moldando os parâmetros para julgar as refeições feitas fora de casa. Essa referência muda ao se considerar aqueles que estão por divertimento na praça de alimentação, o comer reveste-se de sentidos distintos e a casa ganha ares de monotonia e trabalho, especialmente a preparação da refeição, sair para comer permite o acesso a uma refeição incomum em relação àquela realizada no cotidiano.

Essa contradição persistente em muitas entrevistas revelou-se também para Garcia (1993; 1997), que constatou o caráter circunstancial daquilo que seus informantes consideravam melhor, a comida de casa ou de fora desta, mostrando que essas representações do comer são maleáveis, especialmente no discurso. Na prática encontram-se outros arranjos, mediados pelas representações do comer e que serão abordados nos próximos tópicos.

\section{COMER EM CASA}

Ao proceder a uma rápida pincelada na questão do comer, a distinção de alimentar-se em casa e fora desta manifestou-se de modo permanente na fala dos entrevistados. A partir dessas categorias nativas pretende-se refletir sobre aspectos da vida cotidiana moderna, decisão reforçada pelo fato de que entre as pessoas entrevistadas a casa serviu de referência constante na definição do que é uma refeição adequada ou não, sugerindo que a esfera doméstica, pelo menos durante um processo inicial de formação do gosto e do paladar, seria responsável pelas bases necessárias para a construção das representações do comer. 
Para empreender um contraste entre o comer em casa e o comer fora é interessante trabalhar com a noção de refeição, meio através do qual o comer se concretiza ao combinar alimentos, modos de consumo, evento, horário, companhia, status etc - argumentação já apresentada por Douglas (1975). Para essa autora, as refeições apresentam uma estrutura própria, sendo seu consumo uma espécie de atividade ritual, dada a reunião de elementos classificados de formas distintas, organizados hierarquicamente com limites claramente delineados ${ }^{8}$.

Murcott (1995) sugeriu aquilo que poderia ser considerado como uma "refeição apropriada" - Tradução do inglês proper meal. Utilizando o exemplo de uma refeição comum na Inglaterra, o jantar de domingo, a autora colocou-a na posição de refeição ideal, alcançada ao reunir elementos que lhe transmitem essa qualidade: o tipo de alimento, neste caso consistindo em carne e batatas assadas, verduras cozidas no vapor e um molho preparado a partir dos sucos provenientes do processo de cozimento, devendo ser consumida em família, durante o jantar ${ }^{9}$.

Contudo, é preciso ressaltar que para se definir uma refeição como ideal precisa-se levar em conta fatores como a classe social, gênero, idade, formação cultural etc, especialmente ao lembrar de algumas falas coletadas, contraditórias quanto ao que se concebe como uma "refeição ideal". O senhor Alexandre ${ }^{10}$, por exemplo, fala que sua refeição ideal é aquela preparada em casa, de maneira simples, com ingredientes comuns, porém saborosos, e que Ihe trazem "lembranças da Grécia". Essa refeição pode ser compartilhada com a família ou com amigos, estes últimos de maneira a impressioná-los pela capacidade de recebê-los bem, oferecendo um casamento perfeito entre alimentos, bebidas, serviço e companhia. Quando come fora, o senhor Alexandre diz que procura essa mesma simplicidade nos pratos, pois é através dessa característica que percebe a qualidade do alimento e o seu correto preparo. Acrescentou que freqüenta restaurantes de comida rápida por obrigação, quando precisa almoçar rapidamente durante a semana ou com seus netos em dias de descanso, de outro modo prefere restaurantes como o “Gero, esse outro aí na frente do Gero, do lado daquela loja... É o Empório Armani, lá eles fazem coisas que eu gosto, macarrão com azeitonas, simples, simples".

Já E. ${ }^{11}$, da mesma faixa etária que o senhor Alexandre, porém com uma disponibilidade econômica menor, acredita que comer fora só se justifica em grandes ocasiões ou por necessidade, e mesmo assim de maneira restrita. Afirmou que só costuma ir às praças de alimentação quando não lhe resta outra opção, também com os filhos ou netos. Mesmo morando sozinho não se habituou a realizar suas refeições fora de casa, pois aprecia cozinhar e acha o comer um momento especial, sobretudo o preparo da comida que deve ser "à vista... Você tem que ver como a comida está sendo feita", e é por essa razão que, de modo geral, não aprecia restaurantes.

Nesse sentido, E. parte para a cozinha assim como Expedito ${ }^{12}$, que de acordo com sua mulher, acaba responsável pelas refeições durante o fim-de-semana na casa da praia: 
“(...) a gente fica pouco aqui em São Paulo, agora com a casa da praia a gente acaba indo prá lá todo final de semana... Lá é gostoso porque a gente chama o pessoal, às vezes vão os filhos do Expe (é o terceiro casamento de Expedito e ele tem três filhos dos anteriores) e no sábado à noite ele fica fazendo pizza, que é uma delícia. Temos o forno e vão amigos, fica um monte de gente. No domingo é churrasco ou um peixe, caldeirada, que ele também prepara. Todo mundo vai lá prá comer a comida do Expe, a gente fica batendo papo. Às vezes vão nossos pais, mas não é todo final de semana, lá é prá descansar, ficar longe da bagunça daqui".

Entre outros entrevistados com menos possibilidades econômicas ${ }^{13}$, a noção de refeição ideal mostra-se organizada sob parâmetros distintos, referindo-se à refeição preparada pela mãe, conduzida em família aos domingos e na qual o alimento principal consiste de uma massa acompanhada de uma salada ("maionese"), seguidos por uma sobremesa. Outra refeição comum considerada ideal é o churrasco, este normalmente compartilhado com amigos e sob a responsabilidade de preparo dos homens que assam e distribuem a carne, de modo lento e de maneira contínua, normalmente acompanhado de cerveja ${ }^{14}$.

Em dias comuns, o status de refeição ideal respalda-se na presença do arroz e do feijão, sobretudo quando se come fora durante a semana e manifesta-se cansaço com relação ao "tempero de restaurante". Nada substitui um desses alimentos "fresquinhos, feitos em casa, não com aquela cara de dias...", como Herbert"15 comentou. Este último informante adora comer fora mas não em fast-foods em praças de alimentação, pois durante a semana costuma controlar a ingestão de alimentos, no fim-de-semana é quando pode liberar sua dieta. Então, costuma ir a rodízios e pizzarias, seus preferidos.

Para ele, a refeição ideal seria picanha, diariamente. Devido aos seus problema com o peso, tenta manter um cardápio muito exíguo no correr da semana, no qual consome basicamente legumes, verduras e frango grelhado. Ele tampouco se importa muito com aquilo que come em casa, pois como normalmente só janta, em geral sopa, não sente nenhum tipo de apego pelas refeições ali empreendidas, embora considere a alimentação do ambiente doméstico "muito mais saudável do que na rua, pois você não sabe direito o que está comendo".

Importa que “...o espaço fundamental para a memória é a casa” (Harvey 2001:200), pois é onde se está livre para imaginar e construir a noção do que é uma "refeição ideal". A importância do espaço doméstico na constituição das representações do comer surge claramente delineada na fala de Marcela ${ }^{16}$, que resgata memórias da infância ligadas ao alimento:

“(...) sabe do que eu lembro? A macarronada da minha avó! A minha avó quando era viva, a minha avó era daquelas italianonas, fazia uma macarronada... Tradição de família, desde pequeninha... Meu pai pegava eu e minha irmã de pequeninha, no domingo de manhã, saía conosco para passear, passava na casa da minha avó, e minha avó estava fazendo molho de macarronada... A gente pegava o pão, cortava e punha... e comia, e comia aquilo!!! Aí a gente voltava em casa, buscava minha mãe, e a gente voltava para almoçar. Então assim, molho de macarrão prá mim é o molho da minha avó. Minha mãe faz uma belíssima macarronada, até hoje eu lembro do gostinho!" 
Maria Lúcia ${ }^{17}$ também se referiu à casa em diversos momentos de suas conversas. Além de não se sentir bem comendo em frente a outras pessoas que não conhecidas suas, lembrou que:

“...outro dia minha filha sugeriu de sairmos no domingo para comer fora, num rodízio, só para variar, mas eu acho bobagem, eu tenho prazer em cozinhar, não ligo de fazer um prato para cada um, o que eles me pedirem! É que eu também não gosto de comer na frente dos outros, não me sinto bem. Eu gosto de todos meus filhos em volta, prá comer."

Sua filha, Gisele ${ }^{18}$, também considera a casa como o lugar no qual se pode realizar uma refeição ideal, embora o sentido que ela atribui está relacionado ao que entende por saudável, pois é em casa que se pode comer verduras, legumes, frutas - alimentos que considera importantes para a saúde e manutenção do peso. Gisele disse que mesmo sabendo que o “McDonald's é porcaria" gosta de compartilhar um hamburguer e batatas fritas com suas colegas de trabalho após o expediente, para ela uma refeição ideal, embora não da mesma ordem da refeição empreendida no ambiente doméstico.

Murcott (1997) já havia assinalado que a idéia de refeição ideal é um instrumento para a construção da memória e ponto de referência para definir o ato de comer. A casa forneceria os modelos "ideais" para elaborar as idéias do comer que podem ser revistos e adaptados à realidade com a qual se convive, e mesmo não permanecendo fixos ao longo da experiência de vida, moldam as bases para as representações do comer.

\section{COMER FORA}

O valor atribuído pelos entrevistados à refeição empreendida no ambiente doméstico oscila conforme uma série de fatores e mesmo que corresponda a uma imagem idealizada, alimentar-se longe de casa parece ser um processo "imposto" às pessoas recentemente. O fato é que este fenômeno, no decorrer do século XX, tomou um impulso em função das inovações que se desenrolaram na agricultura, na indústria, nos transportes etc. e proporcionou as bases para o surgimento de um amplo espectro de restaurantes, serviços de entrega de comida pronta e mais uma infinita variedade de opções oferecidas para efetuar refeições longe de casa ${ }^{19}$. O hábito de efetuar uma refeição fora de casa tornou-se mais comum para uma ampla parcela da população, especialmente da classe média urbana.

O ato de comer fora no Brasil encontra-se associado a essas transformações, presentes na sociedade de 
modo geral e vislumbradas no crescimento urbano, na expansão industrial, na incorporação da mão-de-obra feminina no mercado de trabalho etc, mudanças presenciadas especialmente a partir da década de 1950, conforme Mello e Novais (1998). Até o final da década de 1970, esse processo passou por uma renovação, uma vez que o país presenciou um boom econômico, promovendo definitivamente a oportunidade de tornar esse hábito uma constante na rotina dos indivíduos ${ }^{20}$. Em um primeiro momento, ainda seguindo esses autores, surgiram vários restaurantes destinados a atender pessoas de maior poder aquisitivo, enquanto botequins e bares destinavam-se aos usuários de possibilidades econômicas mais escassas. As pizzarias, rodízios populares, redes de comida árabe e cantinas italianas instalaram-se e direcionaram suas forças para a classe média urbana, que se expandia visivelmente durante aquele período.

Firmando-se com força, esse hábito hoje sustenta um importante segmento da indústria alimentícia, uma vez que sua participação, levantada entre os anos 1993 e 1999, cresceu na ordem de 16,7\%, assim como se observou um aumento da participação dos gastos com alimentação em refeições fora do lar, representando $21,3 \%$ do total despendido em 1996. No Brasil, é importante distinguir os grandes centros urbanos, nos quais $25 \%$ das refeições realizadas são fora de casa, em comparação às demais regiões, cujo consumo é ligeiramente menor, correspondendo a $20 \%$ do volume total da alimentação fora do lar, conforme dados fornecidos pela ABIA Associação Brasileira da Indústria Alimentícia.

Observando o desempenho que os dados acima apresentados sugerem, essa prática modificou o comer e as relações estabelecidas com o alimento, assim como o hábito de freqüentar restaurantes. Realizar uma refeição fora do lar, tornou-se um hábito difundido, gerando novas interpretações que, expressas na ação social, organizam as escolhas alimentares assim como determinam apropriações e usos de espaços. Da mesma forma que comer em casa, comer fora não é uma experiência equivalente para as pessoas que se encontram consumindo refeições na praça de alimentação. Um primeiro diferencial são as motivações que as levam a esses espaços e que podem ser resumidas basicamente em necessidade e lazer.

Necessidade e lazer ${ }^{21}$ seriam as motivações de comer fora, para Marcela. Para Alexandre, comer em praças de alimentação é uma necessidade imposta pelo trabalho, ao contrário de Gisele e suas amigas de trabalho que apreciam efetuar uma refeição em um fast-food, mesmo podendo comer em casa. Outras pessoas como Luís ${ }^{22}$ e Roberta $^{23}$ freqüentam a praça de alimentação como um lugar no qual é possível reunir-se com amigos e de lá ir ao teatro ou cinema no próprio shopping, ou simplesmente sentar-se na praça para jantar e conversar. 
“...aqui a gente pode sentar e conversar, é um lugar no meio do caminho e dá prá encontrar o pessoal, comer um polpetone ou uma salada, só beber se quiser. Como nem todos têm carro aqui é uma boa, fica central pro resto da turma. Tem o Toli, o Del, o Marco, que trabalham na Santa Casa, saem de lá e encontram a gente aqui, se alguém quiser dá para pegar um cinema".

Este é um comentário de Roberta, ao referir-se à praça de alimentação do shopping Pátio Higienopólis, local que costuma freqüentar com Luís e demais amigos durante a semana no horário do jantar, quando todos saem do trabalho e se congregam para conversar e divertir-se. Embora nem sempre o grupo conte com todos os amigos que o compõem, os amigos têm um dia fixo para essa reunião: quartas à noite.

Fernanda ${ }^{24}$ e seu irmão Caio ${ }^{25}$ comentaram que nunca lhes passaria pela cabeça ir ao shopping só para comer, embora Fernanda ao mudar-se e morar com a mãe, costume usar com freqüência a praça de alimentação do shopping Pátio Higienopólis, sobretudo para jantar à noite. Como moram somente as duas "não vamos fazer comida só para nós duas, fica rodando na geladeira e no fim a gente come prá não estragar e acaba engordando". Acrescenta ainda que, além de jantar na praça de alimentação, gosta de ir ao shopping porque tem diversão garantida, nem que seja para olhar as vitrines. Caio, por sua vez, adora comer e aprecia praças de alimentação, mas como vive de mesada não tem possibilidades de freqüentá-las com muita regularidade. Ele afirmou que o fast-food que conhece é o McDonald's, os demais estabelecimentos "são fast-foods mas não são, sabe? Porque têm comida, então não é fast-food, daí fica só o McDonald's". Questionado sobre o que já tinha experimentado na praça de alimentação, fez um esforço e enumerou o Strogonophy's e BonGrillê, onde às vezes sua madrasta, Ana, funcionária de uma loja do shopping Morumbi, o convida para almoçar ou jantar quando ele vai buscá-la.

Embora sejam visíveis duas motivações imediatas para realizar uma refeição fora de casa, necessidade e lazer, nem todos os restaurantes atendem os seus freqüentadores de modo equivalente. Comer fora sugere para Marcela um peso negativo, por sentir-se prejudicada por não poder realizar suas refeições em casa - "se eu trabalhasse perto de casa ia todo dia comer lá" -, privando-a de um momento agradável de convívio familiar e proximidade com alimentos que a confortam. Em sua busca por lugares para almoçar na praça de alimentação, utiliza somente duas ou três opções das muitas ali disponíveis: o Giácomo, que tem uma comida italiana "boa" com um "tempero gostoso", o Viena Express, pelo seu bufê, e o McDonald's, às sextas-feiras, "sagrado", por sugerir o começo do fim-de-semana: "tem um sabor de festa".

Herbert, ao falar de sua experiência, disse que "fast-food no sentido americano não vou, sabe? Vou no BonGrillê, no AllParmegiana, esses daí, mas no fast-food não! Detesto McDonald's, aquele outro de pizza... o Pizza Hut". Quando come fora, Herbert separa nitidamente os restaurantes que freqüenta durante a semana, no seu horário de almoço, e os que "gosta de ir" no seu período de descanso, normalmente o Barbacoa no shopping 
Morumbi, onde há um "bom rodízio, gosto mais do Barbacoa do Itaim, mas acabo vindo aqui por causa da minha mulher, que quer vir no shopping, gastar". Além dessa separação, destacou-se que a idéia de fast-food está ainda muito conectada à rede McDonald's e outras redes americanas, que via de regra vendem alimentos como hamburgueres, pizzas, sanduíches, pedaços de frango fritos etc, sem muita proximidade do que é convencionado como "comida". Tais estabelecimentos acabam não sendo classificados como restaurantes no sentido tradicional.

Uma primeira classificação mapeada entre os informantes sugeriu o seguinte: existem restaurantes que lembram a casa, restaurantes para saber fofocas, o McDonald's - já que ele é uma categoria afastada das demais redes de fast-food, sendo-Ihe atribuído um lugar único -, estabelecimentos que vendem um determinado tipo de comida (étnicos, "saborosa", "honesta", "razoável"), que são rápidos, que estão sempre vazios, que têm opções para quem faz regime, que sempre têm fila, restaurantes que são caros ou baratos, restaurantes para a família, restaurantes para ir com as crianças, para fazer um lanche depois do cinema, que dão para comer sozinho, restaurantes com tempero bom, com cara de limpos ou cara de sujos, restaurantes com ambiente agradável ${ }^{26}$.

Por outro lado, a classificação dos restaurantes com a qual a pesquisa foi iniciada organizava-se de outra maneira: fast-foods, estabelecimentos que vendem lanches, comida típica, temáticos, quilo, bufês, selfservice, rodízios e mais duas categorias que denominei de descaracterizados ${ }^{27}$. Estes flutuam entre dois ou mais tipos de restaurantes de comida rápida, oferecendo, por exemplo, comida a quilo e lanches, e os híbridos, que importaram alguns elementos de restaurantes convencionais, embora possam ser considerados como restaurantes de comida rápida ou fast-food, já que possuem produção em uma cozinha centralizada. Neste caso, posteriormente os alimentos são distribuídos entre as filiais, garantindo rapidez, sabor equivalente e qualidade, nos mesmos moldes das grandes cadeias de restauração rápida, mas sem deixar de oferecer serviços e produtos como talheres, guardanapos de tecido, garçons para trazer bebidas, conta na mesa, ausência de bandejas, maître para recepcionar os clientes etc ${ }^{28}$.

Assim, um restaurante que é um fast-food no sentido da produção, distribuição e de suas diversas lojas instaladas em shoppings como o América, por exemplo, não entra na classificação dos entrevistados nessa categoria. É considerado um restaurante pelo atendimento feito por garçons, fornecendo um ar mais personalizado e a "comida não é tão ruim como nos outros restaurantes lá da praça, tem um paillard com fettuccine que dá pra comer", como se referiu Sr. Alexandre - embora esse prato seja elaborado fora do próprio local e tenha o mesmo gosto em qualquer outra filial da rede. 
o universo dos estabelecimentos de um modo ímpar, diferente daquele inicialmente proposto no trabalho. Mesmo tendo consciência que o restaurante é de comida a quilo, bufê, de lanche etc, a forma pela qual ele é posicionado está sob a ação de uma lógica que não limita o comer em praças de alimentação à uma escolha pelo alimento. Procurar um restaurante para comprar uma refeição e consumi-la em um espaço comum a outros comensais é uma prática que, coordenada em conjunto com variáveis distintas, organiza uma ação social específica rica de sentidos, um dos quais será abordado no próximo tópico.

\section{O ALIMENTO}

Ao tratar das representações do ato de comer em restaurantes de comida rápida em praças de alimentação localizadas em shopping-centers privilegiou-se a dimensão do consumo, não se tratando, obviamente, do único ângulo pelo qual o tema pode ser trabalhado. Considerando diversas possibilidades de abordagens e a amplitude de enfoques que servem como instrumentos de análise, tem-se plena consciência de que não há possibilidade de incorporar, no presente texto, todos os aspectos envolvidos na construção das idéias relativas ao comer, sobretudo aqueles que se concentram na produção, distribuição e preparo, ou no encaminhamento do lixo alimentício. Esses aspectos, porém, não são de todo afastados da discussão, sendo conectados à análise quando necessário.

Inicialmente, a abordagem que orientou as primeiras investigações de campo estava voltada para a importância do alimento como elemento fundamental para determinar a escolha de um estabelecimento. Com o andamento da pesquisa notou-se que existem outros fatores envolvidos nessa decisão. Ao ser o alicerce de composição da refeição, o alimento encontra-se organizado de modo a constituí-la, sendo capaz de definir aquilo que é "comida" ou "lanche", tipos de restaurantes que vendem refeições adequadas ao horário, à companhia, ao ambiente, à higiene etc.

Mas considerar uma substância, das muitas que estão dispostas na natureza, como alimento, depende de uma série de relações, estabelecidas a partir de um sistema classificatório que concede a qualidade para o consumo ou não ${ }^{29}$. Sem evidentemente esgotar as possibilidades de classificações existentes, percebe-se a extrema flexibilidade com a qual essa categoria pode ser manejada e nesse sentido é possível vislumbrar uma primeira direção sobre a escolha de um determinado estabelecimento para comprar uma refeição, baseada na distinção entre "comida" e "lanche" 30 . Um alimento para transformar-se em comida precisa passar pela aprovação de uma lógica específica ${ }^{31}$ e em linhas gerais a diferenciação encontra-se relacionada ao gênero, camada social, nível econômico, formação cultural, delineando-se uma proximidade com as argumentações defendidas por Bourdieu 
(1979), especialmente no processo de formação do gosto. Esse autor, associando diferentes níveis de aquisição daquilo que ele denominou capital simbólico, estabeleceu as diretrizes das quais o gosto seria derivado, uma vez que o consumo e a utilização de bens culturais estariam conectados à maneira pela qual é adquirido o conhecimento, assim como ao pertencimento a uma determinada classe social, ao meio em que se vive e foi criado, ao tipo de trabalho exercido etc, elementos estes que ao serem reunidos, constituiriam um gosto específico ${ }^{32}$.

Mas a mobilidade das categorias ainda se faz presente em função do lugar no qual o informante se encontra, pois para uns o que é um "lanche" adquire status de refeição, embora não substitua a "comida". Ao conversar com o proprietário de uma pequena rede que vende pizzas em pedaços, Caio Seabra, e questioná-lo sobre os horários nos quais o estabelecimento possuía maior movimento, ele comentou que isso não ocorria porque o produto de sua rede não é "comida",

“é algo mais pra comer no meio das refeições, quer dizer, é o que o pessoal acha. Ninguém almoça um pedaço de pizza, pelo menos normalmente. Só quando não está com tempo e quer dar uma tapeada na fome, daí o pedaço da pizza vende. Dessa forma, não tenho horário de pico, pinga o dia todo"

Essa posição, intermediária, caracteriza um nível distinto adequado somente para "matar a fome”, “dar uma tapeada", como foi presenciado durante as entrevistas, apresentando alimentos concebidos com essa finalidade como salgadinhos, iogurtes, biscoitos, pães, bolos. Questionadas, algumas pessoas comentaram que durante a semana geralmente apelavam para o "lanche" a fim de alimentar-se no horário de almoço, às vezes pelo preço, às vezes pelo tempo escasso e vários afirmaram "não ter almoçado (...) comi um lanche, tipo sanduíche de pão integral, nada de comida".

Está claro que existe uma diferença entre o alimento e a comida, o lanche e a refeição, cada qual ocupando um lugar específico e determinando, em parte, a decisão por um certo estabelecimento. Realizar uma refeição precisa de "comida", do contrário caracteriza-se como "lanche" ou "belisco". A questão ainda subjacente é que o lanche não estaria atendendo às necessidades daquilo que se convencionou como "dieta saudável", já que os alimentos que o compõem são geralmente classificados como "porcarias" ou "tranqueiras", contrariamente ao que se entende por "comida" - em geral ligada à noção do saudável, daquilo que não faz mal, que proporciona bem-estar. J uliana ${ }^{33}$ deixou transparecer:

“(...) vir ao McDonald's é um programa! Durante a semana eu combino com a Gisele e com a Mara (colegas de trabalho) de sair do trabalho e tomar um lanche aqui. A gente vem, come e fica batendo papo, colocando a conversa em dia, porque lá no trabalho não dá e geralmente todo mundo vai comer em casa por causa do horário, das 6:00 às 12:00. (...) Como saudável a semana toda, já me conscientizei disso e mudei meus hábitos. Quando venho ao McDonald's, que eu adoro, como tudo, o sanduíche, a batata e às vezes a tortinha! Mas aí é a única refeição do dia, pois depois preciso controlar para não extrapolar, você sabe né? Eu me preocupo com o peso, com a saúde!" 
J uliana considera o seu almoço - hamburguer, batatas fritas e refrigerante - como uma verdadeira refeição, embora tenha consciência de que não é "saudável", pois não é exatamente "comida". Ela acrescentou, ainda, que sua alimentação é "adequada", uma vez que come com freqüência "comida", ou seja, alimentos saudáveis como verduras, legumes, frutas e pouca carne vermelha, esta última uma ou duas vezes por semana, no máximo.

Não realizar uma refeição considerada ideal revelou-se mais incômodo para os informantes do sexo masculino, pois vários entrevistados afirmaram sua insatisfação quando não podiam comer algo mais "consistente" e precisavam contentar-se com um sanduíche ou salgadinho. A distância entre o que consideram uma refeição "de verdade" e o "lanche" sugeriu ser maior do que aquela encontrada entre as mulheres entrevistadas. Os homens comentavam a falta de "comida", como arroz, feijão, proteína animal (carne, frango etc.) e algum acompanhamento, fato ainda mais marcante entre homens solteiros ou separados. Ao morarem sozinhos, eles valorizam a realização de uma refeição nos moldes ideais, tentando evitar "tranqueiras" tais como sanduíches, pizzas, pastéis, salgadinhos etc. Parte do seu cotidiano alimentar, o consumo das "tranqueiras" resulta de uma estrutura doméstica precária que pouco se assemelha ao ambiente vivenciado junto aos pais ou quando casados.

Rodrigo $^{34}$ acredita que comer um lanche do McDonald's não equivale a uma refeição, pois ele sente falta de "comida",

“Sabe? Assim...eh....arroz, feijão, bife, salada, essas coisas! O McDonald's é lanche, não é almoço ou jantar (...) É que nem outras tranqueiras como pizza, comida chinesa (...), entendeu? Durante o dia eu tento almoçar comida mesmo, tipo arroz, feijão carne, batata frita e salada, mas nem sempre dá, tem dia que a gente sai correndo e come um cachorro-quente ou um sanduíche, porque tem coisa prá fazer e acaba nisso mesmo(...)".

Rodrigo valoriza esse tipo de alimento devido à sua condição doméstica: solteiro e morando com seu pai, raramente compartilham uma refeição juntos. Durante o dia ele tenta "garantir sua porção de comida" já que à noite sabe que dificilmente irá comer algo diferente de pizza ou pastel, a menos que seja convidado para jantar na casa de sua namorada, onde ele acredita poder estar um pouco mais próximo dos padrões “ideais" de refeição, já que a mãe dela prepara a alimentação de toda a família.

Entre pessoas mais velhas e de uma faixa social mais abastada, o julgamento daquilo que é considerado "comida" é bem diferente: J oaquim ${ }^{35}$ não consome fast-food a menos que não lhe reste outra alternativa:

“Pô, comida de fast-food não é comida! Imagina! Como é que alguém vai no McDonald's! Minhas filhas nunca comeram hamburguer (tem duas filhas casadas) e garanto prá você que nunca sentiram falta! Comida boa mesmo é aquela servida em casa, eu só experimentei o sushi, estou aqui por acaso, porque vim comprar o carrinho de bebê do meu neto". 
Tanto para J oaquim como para sua esposa, a comida que é vendida em praças de alimentação é uma "afronta à comida típica, tradicional, bem preparada", já que "não tem gosto de nada, é tudo igual", embora ele não possa saber já que alega só ter consumido comida japonesa. Ele também costuma freqüentar restaurantes caros, hábito comum que também não aprecia: o mantém pelos amigos ou por obrigações profissionais. Em sua opinião, nada do que é oferecido fora de casa tem o mesmo sabor, qualidade ou cuidado na apresentação, porém é consciente de que ao dispor de uma pessoa para preparar as refeições de sua casa, desfruta de uma condição que não equivale à média da maioria das pessoas.

Ricardo ${ }^{36}$ compartilha de idéia semelhante, para ele fast-food não oferece "comida". Embora pertencendo a uma classe social econômica distinta de J oaquim, acredita ser um grande "conhecedor" de assuntos culinários, pois tem extrema habilidade na cozinha e aprecia oferecer grandes almoços em sua casa. Ele comentou que:

“a comida desses lugares (os fast-foods) não tem nada a ver com a de casa, com aquilo que eu preparo, tipo peixe. Eu compro tudo fresco, vou na feira, vou no mercado municipal, você acha que esses restaurantes fazem isso? Vê aquele Vivenda do Camarão, é um horror!"

Outra informante, Conceição ${ }^{37}$, não vê a comida desses estabelecimentos sob o esse mesmo prisma, embora freqüente a praça de alimentação, tenta variar as opções e buscar coisas diferentes daquelas que costuma comer durante a semana de trabalho,

"Ah, para escolher eu dou uma volta, vejo o que eu estou com vontade e daí fico olhando como está a comida, se tiver revirada, feia nem vou (...) Eu adoro o quilo porque dá prá gente escolher, gosto muito daquele Comida Típica da Fazenda - São Paulo II ou o Viena Express (...). Bom, esse eu só fui uma vez porque parece igual com a comida que eu como durante a semana, então não acho muita graça (...). O Axé eu fui, mas é isso que te falei, achei a comida feia, então não me dá vontade de comer (...), mas voltei lá umas duas vezes e acabei gostando. Tem coisas como moqueca de peixe, bobó de camarão e é barato porque com um suco, que eu não costumo tomar toda hora, dá uns sete, oito reais. (...) O Habib's? A comida é horrível, essa não dá vontade mesmo! Eu sei que é barato, mas não dá!"

Para Conceição, o fato de ter muita disponibilidade de comidas diferentes na praça de alimentação não Ihe chamou a atenção, pois procura restaurantes adequados à sua preferência, no caso, aqueles que vendem comida a quilo. Mesmo detentor dessa qualidade, o restaurante pode não integrar seu mapa de opções, para ela comer na praça de alimentação, especialmente quando está em seu período de descanso, precisa notar uma distância da comida consumida diariamente. Procura diversidade no sistema de quilo e não naquilo que está à disposição na praça de alimentação, pois não quer se arriscar a experimentar algo que não venha a apreciar. 
Sua amiga, Cida ${ }^{38}$, que a acompanha de vez em quando em suas visitas aos fast-foods do shopping MetrôTatuapé, disse gostar da variedade da praça, embora não a aproveite. Só come "yakissoba", prato de macarrão, verduras cozidas e carne, "comida japonesa ou chinesa, tem nos dois, sei lá!", seu preferido e portanto quase que sua única opção, independente das demais ofertas à sua volta. J ustifica essa falta de inovação graças à sua falta de habilidade de preparar algo tão simples, mas que ela aprecia consumir quando come fora,

“primeiro eu não gosto de cozinhar e segundo trabalho fora, somos só eu e minha filha que também trabalha fora, você acha que eu vou chegar em casa e cozinhar? Mas nunca! Fora que eu estou sempre sozinha, daí o shopping é legal para ver gente, dar uma volta. Depois de comer vou até o Amor aos Pedaços ou na Ofner e faço uma extravagância, eu adoro doce!"

Os restaurantes aqui organizados sob os parâmetros do "típico" ou do "temático" não se cruzam com a classificação sugerida pelas informantes, pois ao comer na praça de alimentação, para Conceição, por exemplo, tem menos importância o caráter do alimento ou sua ligação com uma região que a forma pela qual ele está apresentado, e o aspecto de limpeza. Cida, sua amiga, prefere não se arriscar com novidades e depois ficar decepcionada. Portanto, se é chinês ou japonês, o prato que ela consome com satisfação é o "yakissoba".

O que se verifica, em uma primeira instância, é que o comer em praças de alimentação está em confronto com o ambiente doméstico, ora no sentido de tentar alcançar sabores semelhantes aos da casa, embora exista a consciência de que é uma ilusão, ora na distância com aquilo que se consome rotineiramente. As bases dessas classificações deslocam-se à medida que estar na praça é uma necessidade ou um divertimento, mas o comer persiste com sua conexão ao lar, positiva ou negativa, mas presente.

As idéias que ordenam esse comer estão além das simples escolhas baseadas na higiene, rapidez e conforto, no saudável, pois todos os restaurantes da praça de alimentação possuem essas características em maior ou menor proporção. As listas variam, mas existem as "porcarias", como Ricardo se referiu ao estabelecimento que vende peixe e frutos do mar ou Rodrigo, quando falou sobre o McDonald's e o "lanche”, como a pizza em pedaços. Do mesmo modo, a distinção de lugares dedicados à "comida" ou que sugerem limpeza, como faz Conceição ao selecionar certos fast-foods que servem refeições a quilo - e nem todos atendem suas expectativas -, separandoos daqueles que sugerem frescor dos alimentos através de sua apresentação e disposição. Estes poucos exemplos mostraram que as representações do comer expressas na ação social nem sempre correspondem ao que é dito, proporcionando elementos para reflexão sobre essa prática cotidiana e universal. 
J anine Helfst Leicht Collaço

\section{ALGUMAS CONCLUSÕES PARCIAIS}

Através do recorte proposto pela pesquisa, as representações do comer em fast-foods em praças de alimentação localizadas em shopping-centers, evidencia-se que não há a pretensão de avaliar o universo do comer integralmente, já que tal empreendimento necessitaria de recursos e tempo além dos quais se dispõe. A escolha aqui realizada foi no sentido de tentar encontrar, através desse modo específico, material para reflexão a respeito da vida moderna e urbana, utilizando o viés do alimento, polissêmico por natureza, mas privilegiado, no sentido de permitir apreender mudanças em pleno movimento na sociedade.

Os indivíduos esforçam-se, no cotidiano, por reproduzir e assimilar ações, repetindo-as de maneira constante para dar forma e sentido ao seu mundo, ao mesmo tempo que essa própria realidade molda sua visão. Para sobreviver no emaranhado de fragmentos que a cidade proporciona, os usuários de praças de alimentação, neste caso específico, prendem-se a um ato ritualizado, a refeição, que concede uma perspectiva para suas ações e comportamentos sociais.

Distanciando o olhar e comparando os espaços observados, num primeiro momento não se conseguiu distinguir nenhuma recorrência que possibilitasse uma reflexão mais profunda. Ao perceber que não era a diferença entre os espaços, mas o comportamento adotado entre os vários freqüentadores, esta sim a recorrência observada, embora com nuances levemente distintas, marcadas pelas diferentes biografias que os indivíduos carregam, percebeu-se que ao sistematizar o ato de comer, há a tentativa de estabelecer-se um ponto de apoio que sirva para definir o que se está fazendo no cotidiano, explicando uma parte de sua posição no mundo e dando sentido aos seus modos de fazer. A casa, nesse sentido, é o primeiro parâmetro com o qual o indivíduo se depara para compor suas idéias a respeito do alimento, da alimentação, do ato de comer, fornecendo segurança para desempenhar outros papéis além desse espaço e servindo de modelo para distinguir o eu do outro.

Ao considerar esses aspectos, foi possível identificar entre os informantes a existência de diferentes razões que determinam o comer fora e seus significados, já que não há indicações de um único tipo de procedimento. Realizar uma refeição e classificá-la, depende inicialmente do tipo de alimentação que será empreendida, do motivo pelo qual as pessoas estão se dirigindo a um lugar específico a fim de efetuar uma refeição, que ainda encerra outros aspectos potenciais envolvidos nesse processo, como a espécie de comida servida, o horário, a companhia etc, e que acabam caracterizando um tipo de evento destinado que caberá também em um certo tipo de restaurante.

Através da análise dos dados verificou-se que a importância do alimento na organização das escolhas dos 
estabelecimentos não reinou absoluta na determinação do tipo de refeição que será realizada, nem tampouco no restaurante selecionado. Pensando num primeiro momento que a reprodução dos valores constituídos no ambiente doméstico seria vinculada ao alimento, especialmente na forma do tradicional arroz e feijão, notou-se que os usuários não se utilizam dessa variável, pois em suas falas e em suas ações verificou-se que essas comidas, ou outras preparadas em casa, pouco lembram aquilo que é consumido em praças de alimentação e a proximidade com o lar não é conseguida através do alimento.

O alicerce deslocou-se do alimento em direção à refeição, sem necessariamente especificar quais os elementos que a constituem e dessa forma a casa fornece o suporte necessário para a compreensão do que é uma refeição. Assim, sua estrutura organiza a semana, demarca o tempo, a companhia, as boas maneiras, delimitando fronteiras e limites, como já bem tinham sugerido Douglas (1975) e Murcott (1995; 1997).

Freqüentar praças de alimentação em shopping-centers embora tenham seu lado prático, no sentido de atender necessidades imediatas de alimentação de pessoas que trabalham, incorporando rapidez, higiene e agilidade, não cria uma apropriação generalizada dos restaurantes, ao contrário, a diversidade e a multiplicidade de arranjos é que proporcionam a riqueza para o olhar antropológico.

Janine Helfst Leicht Collaço é mestre em Antropologia Social pela USP, pesquisadora do NAU/USP e professora da Universidade Anhembi-M orumbi. 
J anine Helfst Leicht Collaço

\section{NOTAS}

1 Nesse sentido, ver Rial (1992), Abdala (1997) e Garcia (1993), entre outros.

2 Para mais detalhes ver Flandrin \&Montanari (1998) e Chang (1977).

3 Para efeitos deste trabalho, restaurantes de comida rápida e fast-foods serão entendidos como sinônimos e em oposição aos restaurantes tradicionais. Alguns pontos demarcam a distinção no preparo dos alimentos, uma vez que restaurantes de comida rápida encontram-se organizados sob um padrão industrial, mais uniforme e menos sujeitos à sazonalidade dos produtos. Esse procedimento é normalmente feito em uma cozinha centralizada, com distribuição posterior do alimento entre as filiais, chegando o prato a ser finalizado somente no ponto de venda final. A conseqüência deste método de produção é um prato padronizado em qualquer loja da rede, entregue rapidamente e com um custo menor se comparado a restaurantes tradicionais. Contam ainda com a ausência de mão-de-obra como garçons, assistentes, cozinheiros etc. Os cardápios tornam-se enxutos de modo a trabalhar com uma variedade de pratos menor do que aquela encontrada em um restaurante convencional. A estrutura desse modelo produtivo manipula poucos ingrendientes mas produz em larga escala. Gostaria de salientar que neste trabalho os restaurantes de comida a quilo serão considerados fast-foods, embora não sejam redes e nem tampouco possuam um local central para o preparo dos pratos, que são elaborados no próprio estabelecimento. Eles permitem realizar uma refeição de modo rápido e com um custo moderado, regulado pela própria pessoa através do peso dos alimentos escolhidos.

4 A respeito desse assunto, ver a matéria de capa da revista publicada pela Alshop - Associação de Lojistas de Shopping Centers, ano 7, número 76, dezembro/2001, enunciando o rápido crescimento de tais espaços.

5 A seleção das praças de alimentação foi feita com o intuito de tentar englobar a maior diversidade cultural, assim como possibilitar a abordagem das dinâmicas do comer e da apropriação espacial. Assim, foram privilegiadas três praças de alimentação: o shopping Metrô-Tatuapé - uma escolha baseada em uma característica distintiva dos demais, com acesso facilitado pelo uso de um meio de transporte coletivo; o shopping Morumbi - que concentra um fluxo de pessoas que o freqüentam no horário de almoço devido aos escritórios e fábricas localizados nas proximidades, no fim-de-semana recebendo pessoas de um poder aquisitivo mais elevado, em geral moradores das redondezas de bairros como o Morumbi, Brooklin, Chácara Flora, Chácara Santo Antônio etc; e o shopping Pátio Higienopólis -que após a polêmica que envolveu sua instalação no bairro de mesmo nome, tomou-se um ponto de encontro de moradores das proximidades e de diferentes grupos como senhores e senhoras de terceira idade, jovens estudantes dos colégios próximos, famílias de origem judaica ortodoxa etc.

6 Um exemplo que pode ajudar essa problemática atual são os produtos transgênicos, os quais possuem uma maior facilidade de cultivo embora não sejam tidos "bons para comer", apesar da constante divulgação de resultados de pesquisas científicas isentando-os de periculosidade para a saúde.

7 Douglas (1975) inicia a argumentação daquilo que se pode convencionar como refeição ideal, sendo mais tarde revista por Murcott $(1995,1997)$.

8 Para críticas a essa argumentação ver Goody (1982) e Warde \&Martens (2000).

9 A autora lembra que mesmo utilizando a palavra dinner (jantar) não necessariamente refere-se a essa refeição, pode-se tratar daquela que transcorre aos domingos por volta das 16:00 ou 17:00, espécie de almoço tardio.

$10 \mathrm{Sr}$. Alexandre é proprietário de uma empresa que atua na área financeira e de câmbio, é casado e tem mais de 70 anos. Sua nacionalidade é grega e mora no Brasil há aproximadamente trinta anos.

11 E. pediu para não ser identificado pois é um arquiteto famoso e não aprecia muito shoppings e praças de alimentação, possui três filhos e vários netos e já foi casado três vezes. Uma de suas esposas foi proprietária de um restaurante conhecido em São Paulo na década de 80.

12 Expedito tem 39 anos e é um executivo bem sucedido atuando no mercado financeiro. Durante a semana freqüenta praças de alimentação, às vezes com clientes e nesse momento dirige-se a restaurantes como o América, Ráscal. De outro modo, come algo rápido nas opções oferecidas pela praça. 
13 Entre estes estavam Rodrigo, Cida, Conceição, J uliana, Caio, Fernanda.

14 Maciel (1996) descreve o ritual do churrasco em detalhes.

15 Herbert, trinta anos, é casado com um filho de meses, era funcionário de uma corretora. Costuma freqüentar as praças de alimentação do Morumbi no fim-de-semana, especialmente o Barbacoa. Sua esposa é professora de ginástica e preocupada com a saúde.

16 Marcela, vinte e cinco anos, solteira morando com seus pais no bairro de Santana, era funcionária da área de marketing do Hospital Samaritano e costumava freqüentar a praça de alimentação do shopping Pátio Higienópolis. Ao mudar de emprego, passou a almoçar nas proximidades de sua nova empresa, localizada próxima ao shopping Morumbi.

17 Maria Lúcia, cinqüenta anos, é casada e mãe de três filhos, trabalha como esteticista, prestando serviços nas casas das clientes e mora no bairro do Tatuapé.

18 Gisele, vinte e seis anos, mora junto com os pais e trabalha como fisioterapeuta no Hospital Santa Marcelina.

19 Warde \&Martens (2000) consideram o comer fora qualquer refeição realizada longe de casa, podendo ocorrer em casa de amigos ou parentes, em cantinas de escola, refeitórios de empresas, traillers de cachorro-quente etc. e não só em restaurantes.

20 Conforme dados fornecidos pela ABIA - Associação Brasileira da Indústria de Alimentação -, a participação das mulheres no mercado de trabalho era, em 1971, de $23 \%$ do efetivo total. Elas demoravam 2 horas preparando uma refeição e os gastos mensais com alimentação eram feitos 92,5\% em casa e 7,5\% fora desta. Entre 1997/1998, o efetivo de mulheres que trabalham fora subiu para 40\%, gastando 15 minutos no preparo de uma refeição, as despesas com alimentação em casa ficaram em tomo de $88,1 \%$ e fora desta $11,9 \%$.

21 Segundo Warde \&Martens (2000) outra motivação encontrada entre seus entrevistados residia no prazer, especialmente entre donasde-casa que apreciavam sair para comer fora a fim de liberar-se das tarefas domésticas, sobretudo da refeição familiar e seu preparo. É preciso lembrar que esta pesquisa foi conduzida na Grã-Bretanha, país no qual não se conta com o auxílio de empregados para as tarefas do lar e tal situação não se verificou entre pessoas aqui entrevistadas.

22 Luís, vinte e sete anos, é analista de sistemas, está acabando a faculdade e mora no bairro de Santa Cecília, junto com sua mãe, irmão e avó.

23 Roberta, vinte e seis anos, é assistente administrativa de uma fábrica de móveis, mora com seus pais no bairro do Limão.

24 Fernanda, vinte anos, é solteira e mora com sua mãe na Vila Buarque (próximo à Santa Casa), estuda pedagogia na PUC.

25 Caio, dezoito anos, é irmão de Fernanda e mora com seu pai na Chácara Flora. Atualmente está estudando para prestar vestibular em Arquitetura, sua namorada Samira sempre o acompanha em seus passeios.

26 Finkelstein (1989) forneceu outra classificação: restaurantes especiais, que podem ser formais ou informais, restaurantes para divertirse, que concentram os cafés elegantes e os bistrôs com charme, e restaurantes de conveniência, como restaurantes de bairro, as redes de fast-food e os temáticos. Outra classificação, fornecida pela Embratur, é interessante para ser confrontada com o mapeamento nativo, ao dividir em duas grandes categorias os restaurantes: internacionais (hotéis, resorts etc) e comerciais, estes abrangendo os restaurantes tradicionais, churrascarias, chopperias, típicos (região, país ou gênero de produto), lanchonetes, snack-bar, coffee shop, fast-food, restaurantes self-service, de auto-estrada, casas e bares de entretenimento, quiosques, traillers, buffets.

27 Nessa categoria poderiam ser mencionados as redes Habib's (fast-food de comida árabe e quilo composto de saladas, arroz, feijão e carnes) e Viena Express, a quilo, com lanches e pratos sob encomenda no balcão.

28 Exemplos dessa categoria podem ser citados América, Ráscal, Andiamo, Almanara e Galeto's, entre outros.

29 Discussão revisada em diversos momentos: Sahlins (1976), Harris (1997), Simoons (1994).

30 Ver Sahlins (1976), Harris (1997), Zaluar (1985), DaMatta (1999), Rial (1992), Garcia (1993; 1997), Kant de Lima (1993). 
J anine Helfst Leicht Collaço

31 Kant de Lima (1993) observou essa distinção ao relatar um fato ocorrido na década de 80 no Rio de J aneiro quando ocorreu um desabastecimento de feijão preto, imediatamente substituído por outro que não foi consumido, revelando que o primeiro tipo desse feijão era considerado "comida", ao contrário do outro que não se encaixava nessa categoria.

32 De Certeau (1998) criticou essa abordagem. Rial (1992) também abordou a questão.

33 J uliana, vinte e quatro anos, é fisioterapeuta e trabalha junto com Gisele no Hospital Santa Marcelina. Reside em São Miguel Paulista com seus pais e avós.

34 Rodrigo, dezenove anos, é operador de Bolsa e freqüenta fast-foods em praças de alimentação no fim-de-semana. Reside com seu pai no bairro da Freguesia do Ó.

35 J oaquim, sessenta e cinco anos, é industrial e costuma ir ao shopping Morumbi junto com sua esposa. As filhas já estão casadas.

36 Ricardo, vinte e oito anos, é funcionário do Sr. Alexandre mora na zona Norte.

37 Conceição, quarenta e cinco anos, presta serviços para idosos e bebês recém-nascidos e mora no Brás, sozinha.

38 Cida, cinqüenta anos, é vizinha de prédio de Conceição, freqüentam juntas praças de alimentação sempre que podem. Ela é secretária e mora com sua filha de dezoito anos. 


\section{REFERÊNCIAS BIBLIOGRÁFICAS}

ABDALA, Mônica. 1999. "Self-services: espaços de uma nova cena familiar". In: Caderno Espaço Feminino vol. 6, n.6. BOURDIEU, Pierre. 1979. La Distinction. Paris: Éditions Gallimard.

BRILLAT-SAVARIN. 1995. A Fisiologia do Gosto. São Paulo: Cia . das Letras.

CAPLAN, Pat. 1997. Food, Health and Identity. London: Routledge.

CHANG, K. C. (org.) 1977. Food in Chinese Culture. New Heaven: Yale University Press.

COUNIHAN, Carole \& VAN ESTERIK, Penny (orgs.). 1907. Food and Culture. New York: Routledge.

Da MATTA, Roberto. 1997. A Casa e a Rua. Rio de J aneiro: Rocco.

. 1999. O que faz o Brasil, Brasil?. Rio de J aneiro: Rocco.

De CERTEAU, Michel. 1998. A Invenção do Cotidiano. Petrópolis: Vozes.

DOUGLAS, Mary. 1975. Implicit Meanings. London: Routledge \& Kegan Paul. . 1988. Purity and Danger. London: Routledge \& Kegan Paul.

FALK, P. 1994. The Consuming Body. London: Sage.

FIDDES, Nick. 1995. “The omnivore's paradox". In D. Marshall (org.) Food Choice and the Consumer. Glasgow: Blackie Academic \& Professional.

FINKELSTEIN, J oanne. 1989. Dinning Out. New York: New York Universtiy Press.

. 1998. "Dinning out: the hipperreality of appetite". In R. Scapp \& B. Seitz (orgs) Eating Culture. Albany: State University of New York Press.

FISCHLER, Claude. 1990. L'Homnivore. Paris: Édition Odile J acob.

FLANDRIN, J ean-Louis \& MONTANARI, Massimo. 1998. História da Alimentação. São Paulo: Estação Liberdade.

FORJ AZ, Maria Cecília. 1988. "Lazer e consumo cultural das elites". In: Revista Brasileira de Ciências Sociais vol. 3, no. 6.

FRUGOLI J R., Heitor. 1989. "Os Shopping-Centers de São Paulo e as Formas de Sociabilidade no Contexto Urbano". Dissertação. São Paulo: FFLCH - USP.

GARCIA, Rosa Wanda Diez. 1993. “Representações Sociais da Comida no Meio Urbano. Um Estudo no Centro da Cidade de São Paulo". Dissertação. São Paulo: IP - USP

GARCIA, Rosa Wanda Diez. 1997. “Práticas e comportamento alimentar no meio urbano: um estudo no centro da cidade de São Paulo". Caderno Saúde Pública 13.

GIDDENS, Anthony. 1996. As Consequências da Modernidade. São Paulo: Unesp.

GOODY, J ack. 1982 Cooking, Cuisine and Class. Cambridge: Cambridge University Press.

HARRIS, MARVIN. 1997. Bueno para Comer. Madri: Alianza Editorial.

HARVEY, David. 2001. A Condição Pós-Moderna. Lisboa: Edições Loyola. 
J anine Helfst Leicht Collaço

KANT DE LIMA, Roberto. 1993. “Cultura do desperdício ou política da opulência?". In E. M. Eigenheer (org.) Raízes do Desperdício. Rio de J aneiro: ISER.

LUPTON, Deborah. 1996. Food, Body and the Self. London: Sage.

MACIEL, Maria Eunice. 1996. “Churrasco à gaúcha”. In: Horizontes Antropológicos 4.

MAGNANI, J osé Guilherme C. \&TORRES, Lilian de Lucca (orgs.) 2000. Na Metrópole. São Paulo: EDUSP.

MARSHALL, David. 1995. “Eating at home: Meals and food choice”. In D. Marshall (org.) Food Choice and the Consumer. Glasgow, Blackie Academic \& Professional.

MENNELL, Stephen. 1996. All Manners of Food. Illinois: University of Illinois Press.

MELLO, J oão Manuel Cardoso \&NOVAIS, Fernando. 1998. "Capitalismo tardio e sociabilidade moderna”. In L.M. Schwarcz (org). História da Vida Privada no Brasil. São Paulo: Cia. das Letras.

MURCOTT, Anne. 1997. "Family meals - a thing of the past?". In P. Caplan (org.) Food, Health and Identity. London: Routledge.

1995 "Raw, cooked and proper meals at home". In D. Marshall (org.) Food Choice and the Consumer. Glasgow: Blackie Academic \& Professional.

PITTE, J ean-Robert \&LEMPS, Alain. 1990. Les Restaurants dans le Monde à Travers les Âges. Paris: Éditions Gallimard.

RIAL, Carmem. 1992. Le goût et l'image: ça se passe comme ça chez les fast-foods - étud anthropologicque de la restauration rapide. Université de Paris Descartes, Sorbonne.

. 1996. "Rumores sobre alimentos: o caso dos fast-foods". In: Antropologia em Primeira Mão UFSC. 1996. "Fast-food: a nostalgia da estrutura perdida”. In: Horizontes Antropológicos, número 4.

SAHLINS, Marshall. 1979. Cultura e Razão Prática. Rio de J aneiro: Zahar Editores.

SIMOONS, Frederick. 1994. Eat not this Flesh. Wisconsin: The University of Wisconsin Press.

SPANG, Rebecca. 2000. The Invention of the Restaurant. Harvard: Harvard University Press.

WARDE, Alan \& Martens, Lydia. 2000. Eating Out. Cambridge: Cambridge University Press.

ZALUAR, Alba. 1985. A Máquina e a Revolta. São Paulo: Brasiliense. 


\section{Um Olhar Antropológico sobre o Hábito de Comer Fora} RESUMO

O presente artigo aborda questões relacionadas às representações do ato de comer em fast-foods. Para tanto foram selecionados espaços que apresentassem uma grande concentração desses estabelecimentos, direcionando o interesse às praças de alimentação localizadas em shopping-centers. Incorporando discusssões teóricas recentes, partiu-se para a análise dos dados recolhidos durante a pesquisa de campo, organizando-se de modo a constituir um aprofundamento na questão do alimento, do consumo, do ato de comer, da noção de refeição, analisando através do contraste entre o comer em casa e o comer fora, a formação algumas representações do comer.

PALAVRAS-CHAVE: antropologia urbana, alimento, comer, refeições, fast-foods

\section{A Anthropological View of the Habit of Eating Out}

\section{ABSTRACT}

This article analyses questions related to the representations of the act of eating in fast-food restaurants, selecting spaces presenting a concentration of such restaurants, focusing on shopping centers "food plazas". Incorporating recent theoretical discussions, the organization of data collected in field work presented here constitutes an appreciation of the questions of nourishment, consuming, eating, the notion of meal, analyzing the formation of some representations of the act of eating through the opposition "eating in"/ "eating out".

KEY WORDS: urban anthropology, food, eating, nourishment, fast-foods 